Original Research Article

\title{
A Brief Discussion on the Structure Establishment of Scientific Research Education System and the Improvement of Talent Training Quality
}

\author{
Xiaoming Li* \\ Dalian University of Technology, Dalian, Liaoning 116024, China.
}

\begin{abstract}
In contemporary China, education needs to adapt to the development of science and technology to form a reasonable structural system. The ultimate goal of educating students is to cultivate talents, improve the comprehensive quality of contemporary young people, and create a group of people who can contribute to the country and society. The combination of educational methods and technology can effectively cultivate students' various talents. Through the power of scientific and technological innovation, all students in the learning structure, learning methods and learning process are carried out through effective scientific research methods. Therefore, this article explains how to effectively conduct scientific research and Education. Moreover, it explains how to improve the quality of talent training.
\end{abstract}

Keywords: Scientific Research Education; Talent Training

In today's world, the modern knowledge economy with advanced knowledge and technology as the development foundation and advanced innovative technology as the driving force for development puts forward a higher and far-reaching requirement for the development of higher education. To carry out corporate innovation culture education based on the construction of corporate quality education and to explore the establishment of a new development path for cultivating high-level quality professional innovative technical talents become a major historical mission for higher education to adapt to China' social and economic development and become the objective development requirements of China' knowledge economy in the new era. As a professional training and education base for scientific and technological talents in the active military, the Military Academy is responsible for the historical mission of delivering high-level and high-quality scientific and technological compound professionals to active military members. The "Chinese People's Liberation Army College Education Regulations" clearly stipulates that one of the three primary tasks for colleges and universities to carry out scientific and technological research and development is to serve the development of talents in colleges and universities ${ }^{[1]}$.

The assessment of innovation ability of science and technology major is an organic part of the structure of comprehensive intelligence ability of college students, and it is one of the important basis for schools to measure outstanding talents. In recent years, our college has taken the ideological and practical work of undergraduate education in China's military academies during the new normal period as the theoretical guidance, closely integrated with the basic characteristics and development laws of undergraduate education in China's military academies, and followed "research as the guide, teaching as the basis, and scientific research as the basis. Teaching and teaching are based on scientific research" teaching guiding ideology, with "teaching and research interaction, virtuous circle" as the breakthrough point of teaching, in line with the teaching principle of "strengthening innovation, quick results", in our university's third, fourth and fifth undergraduate students In the process of talent training and education, we will comprehensively carry out inviting teaching and scientific research to establish an educational innovation mechanism, vigorously carry out various forms of military science and technology innovation training activities, and encourage, guide and support our undergraduate students to sign up for military science and technology research skills training as soon as possible It promotes the continuous cultivation of the innovative and entrepreneurial spirit of the undergraduate team and the continuous improvement of independent innovation capabilities.

\section{Strengthen guidance and improve ideological understanding}

They attach great importance to organizing trainees to participate in scientific and technological innovation practice activities and to go deep into the workers' base to conduct ideological and political mobilization of trainees. The leaders at all levels of the

Copyright (C) 2020 Xiaoming Li

doi: 10.18282/l-e.v9i4.1669

This is an open-access article distributed under the terms of the Creative Commons Attribution Non-Commercial License (http://creativecommons.org/licenses/by-nc/4.0/), which permits unrestricted non-commercial use, distribution, and reproduction in any medium, provided the original work is properly cited. 
college and the functional departments of the provincial agencies must change new ideas and fully realize the positive importance of organizing and guiding students to participate in scientific and technological innovation practice activities, and guide students to actively participate in the college's scientific and technological innovation practice activities training. As an important activity content for learning to participate in professional political learning and military training, they should seriously learn to organize and implement and increase the useful guidance for students to actively participate in the school's scientific and technological innovation-related activities, and help the majority of students to fully understand and participate in science and technology. The close relationship between technological innovation-related activities and their own research work management learning. They need to closely connect the professional knowledge and learning needs of students involved in scientific and technological innovation-related activities, closely connect with future jobs and job development needs, and closely connect with daily scientific research, management, learning and life needs Come together. They should take teaching-related management measures in a conscious plan and purposeful manner based on the actual development of the teaching and management research tasks of the majors currently studied by the majority of students and the departments of the affiliated colleges and departments, based on the actual needs of our school's teaching management. They arrange the students to actively participate in our school's science and technology innovation-related activities through scientific arrangements, flexibly and rationally regulate the actual process of students participating in teaching research, and fully mobilize the students' enthusiasm, initiative and practical creativity in actively participating in our school's science and technology innovation-related activities .

\section{Strengthen management and improve rules and regulations}

In order to maintain the correct direction of students' scientific and technological innovation activities, establish a normal order of activities and improve the overall effectiveness of the activities, the college has formulated and issued the "Interim Measures for the Management of Students' Scientific and Technological Innovation Activities", "Interim Measures for the Management of Students' Science and Technology Innovation Fund Projects" and other rules and regulations It effectively regulates the content and form of students' scientific and technological innovation activities, forms a good competition, incentive, supervision, evaluation and guarantee mechanism, and improves the efficiency and quality of scientific and technological innovation activities. In the course of the activity, the college will conduct small inspections from time to time and organize major inspections regularly. At the end of the activity review, a review panel composed of members of the academic committee of the college or hired experts from outside units will comment and score each scientific and technological innovation activity, so that the participants can truly understand their own strength and master the field research direction. Strictly control the use of funds, so that every penny of the fund for scientific and technological innovation activities is spent on the blade, so that the students "dare to spend money and will spend money" in the process of participating in the activities. (figure1)

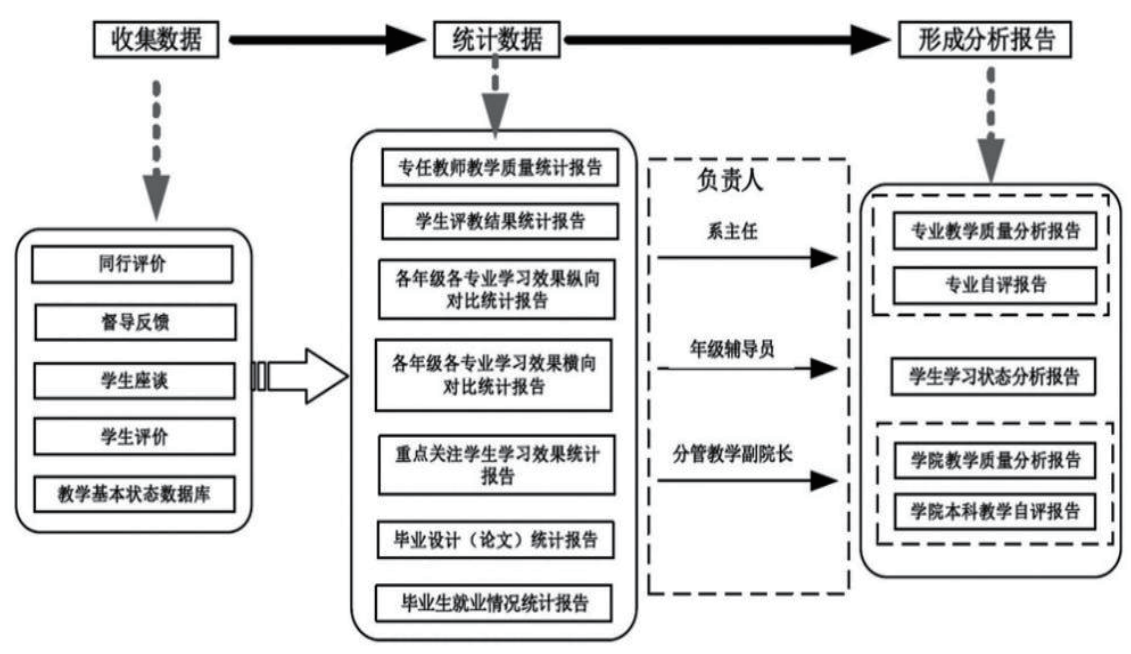

Figure 1. Establishment normal management of teaching mechanism

At the same time, the scientific research management system of the students during school also needs to be optimized at the same time. Optimizing the scientific research management system is to attach great importance to the guidance of the political direction of the scientific research team and the ideological check. The government should use independent scientific research projects to guide the school's scientific research to target the major needs of the national development strategy and local economic construction, and to establish the awareness of researchers for scientific research to serve social and economic construction and to encourage scientific researchers to condense and produce good results, and actively incubate the results. Transformation is applied to local economic development and industrial technology upgrading and transformation.

\section{Increase investment and improve incentive mechanism}

The college should establish a standardized evaluation and reward mechanism. Through the overall planning of the evaluation activities, a complete set of evaluation mechanism with strict organization, complete system, transparent rules and strong operability has been established. For the students who have achieved results, there are effective measures in the aspects 
of evaluation, awards, postgraduate entrance examinations, graduation distribution, etc. The purpose is to fully stimulate the potential of the students and make the students who participate in scientific and technological innovation activities have greater interest. For teachers who instruct students to participate in scientific and technological innovation activities, his workload will be included in the teaching workload, and excellent instructors will be selected and rewarded to maximize the enthusiasm of instructors to guide students. For organizing students to participate in many scientific and technological innovation activities with good results, the whole hospital will be commended. Special funds are allocated from the scientific research management commission fee to establish a special fund for students' scientific and technological innovation, which provides a strong guarantee for students to participate in scientific research training. In formulating academic quality evaluation standards, I emphasize the importance of educating scientific research talents and benchmarking the "Double First Class" academic evaluation standards. We should establish a comprehensive classified academic evaluation standard system, carry out multiple academic evaluations, focus on reflecting iconic research results, and combine with industry academic evaluation standards suitable for the same industry and experts, and have different academic evaluation standards at different stages of career technology development in different fields. guide. At the same time, by improving the talent recruitment mechanism of personnel departments at all levels, establish a systematic evaluation and assessment system for talent recruitment, and a talent recruitment and hiring incentive mechanism that can be entered and released. In the process of revising the standard for the evaluation of professional titles, "being an academic tutor for undergraduates, guiding students' extracurricular innovative practice projects, and other related work to cultivate and improve students' professional ability" is included as the content of the professional title evaluation standard. In the process of recommending professional honor certificates and teaching scholarships for college teachers, whether they can undertake the tasks of opening elective courses for undergraduates and guiding outstanding students is one of the important indicators of teacher evaluation. Encourage and support high-end technological achievements, promote the transformation of high-end technological achievements, encourage technological crossover of key disciplines and strengthen collaborative technological innovation among disciplines.

\section{Increase publicity and create a good scientific and technological atmosphere}

It is necessary to actively carry out academic exchanges and create a good knowledge innovation and active innovation atmosphere. Organize student "Science and Technology Academic Month" activities every year, set up "Expert Forum", "Undergraduate Academic Seminar" and "Undergraduate Top Ten Graduation Thesis Selection" activities. Hire outside experts, well-known professors, celebrities and outstanding young and middle-aged subjects. The leader holds regular academic report meetings. Organizes the compilation of the "Undergraduate Excellent Science and Technology Papers Award-winning Collection" and the "Compendium of Student Science and Technology Innovation Fund Project Achievements", and distributes them to the student team, and issues related management methods for student science and technology innovation activities to everyone A student at school makes scientific and technological innovation activities deeply popular. Through the promotion and reporting of scientific and technological innovation activities, rewards and commendations for students who have achieved achievements, and the use of board newspapers, radio, newspapers, and campus networks to participate in scientific and technological innovation activities Extensive reports by the trainees have enabled the trainees to deeply understand the importance of participating in scientific and technological innovation activities and stimulate the enthusiasm of the trainees to participate in scientific and technological innovation activities. (Figure 2)

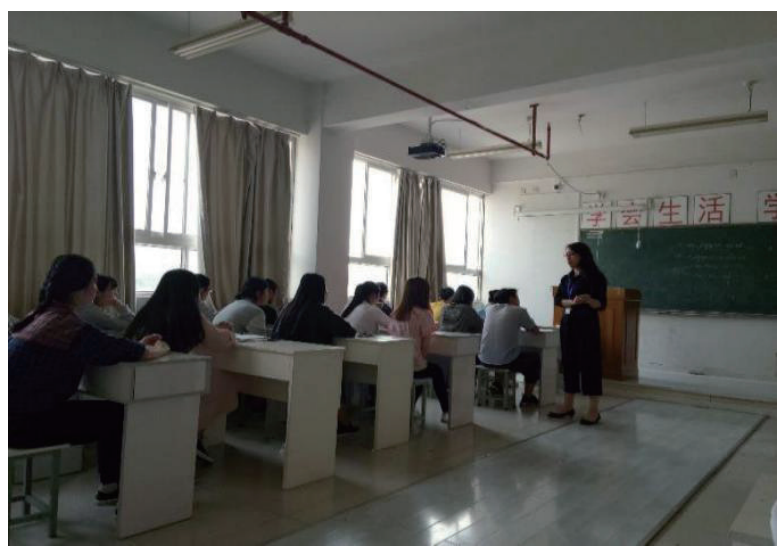

Figure 2. Create a technological atmosphere

\section{Expand ideas and enrich the organization forms of activities}

The student science and technology innovation activities are divided into four categories according to the different organizational forms: one is the project research type, which refers to the student science and technology innovation fund project group that is applied by the student and approved by the college; the second is the group collaboration type, that is, the department and team apply Various large-scale activity groups approved by the college, such as: sand table production group, aircraft model group, etc.; the third is an independent completion type, where students propose ideas for scientific research or academic activities according to their own development needs. After approval by the college, the students will be independent Completed scientific and technological activities, such as small productions and small inventions completed by individual students; the fourth is a 


\title{
The Enlightenment of Japan's preschool education to China's preschool children's social education
}

\author{
Guoliang $\mathrm{Li}^{1}$, Weiwei $\mathrm{Cao}^{2}$, Wanting $\mathrm{Yi}^{3}$ \\ 1. Hunan University of Arts and Science; \\ 2. Hunan University of Arts and Science; \\ 3. Assistant Professor, Keimyung University, South Korea
}

\begin{abstract}
Japan's pre-school education is at the leading level in the world. The success of Japan's pre-school education has a great relationship with Japan's economic development level and Japan's emphasis on education. There are many ideas and methods of pre-school education in Japan that we can learn from. For example, we should pay attention to the mutual penetration of goals in different fields in early childhood education, and attach importance to children's experience in educational activities. The preschool education in Japan not only pays attention to the cultivation of children's awareness and good behavior habits, but also pays more attention to the education of children's survival ability. Through the loose and orderly education environment, children's thinking ability can be well trained, and children's growth and development can be promoted.

Keywords:Japan; preschool education; China; social education; enlightenment
\end{abstract}

\section{Introduction}

Preschool education is an important form of early childhood education in China, but also an important content of international common concern. The quality of preschool education is directly related to children's future growth and intellectual development. In the process of preschool education and development, we can learn from Japan's advanced ideas in preschool education. Since 1889, Japan has formulated various goals to promote children's growth and development, and then gradually improved the relevant laws and regulations, making Japan's preschool education more standardized, which plays a very important role in promoting children's growth and national quality.

\section{Analysis of the characteristics of Japanese preschool education}

Japan uses legal means in preschool education to provide legal security for preschool education, and also makes the management of preschool education more standardized. Japan's pre-school education is a "two track system". The first track refers to kindergartens. The main group of education is children aged 3-5, which is also the pre-school education institutions for children

Copyright $(2020$ Li Guoliang et al.

doi: $10.18282 / 1-$ e.v9i4.1670

This is an open-access article distributed under the terms of the Creative Commons Attribution Non-Commercial License (http://creativecommons.org/licenses/by-nc/4.0/), which permits unrestricted non-commercial use, distribution, and reproduction in any medium, provided the original work is properly cited.

collective organization type, where the department or student team organizes the scientific and technological innovation activities of the students collectively, such as holding scientific knowledge lectures, visiting science and technology exhibitions, etc. When carrying out undergraduate students' participation in scientific and technological innovation activities, they do not blindly seek more innovations, but train them in stages according to their actual abilities. In the content of the students' scientific and technological innovation activities, adhere to the principle of "Grasping science popularization and small production in the third grade, grasping small essays in the fourth grade, and combining the graduation design to grasp the research of invention and creation". The main task of the students is to learn. Not all students participate in scientific and technological innovation activities. We encourage those who have spare capacity and good grades to participate in scientific and technological innovation activities, and encourage students to participate in scientific and technological innovation activities without affecting normal learning. After the third-year students are diverted to professional colleges, a tutorial system is implemented to guide high-grade students to lead low-grade students to participate in scientific and technological innovation activities, with graduation design, practical teaching, and dissertation research as the integration point, to absorb them to participate in scientific research pro ects.

\section{References}

[1]Zhou Yuanyuan; A study on the establishment of a cooperative and diversified talent training model for music Performance majors in colleges and universities; Academic Annual Meeting of Liaoning Higher Education Society; 2017 